\title{
THE IMPACT OF CHILDHOOD FAMILY EXPERIENCE ON PARTNERSHIP PROBLEMS AND BIRTH-RATE IN ADULTHOOD
}

\author{
Indra Tretjakova
}

Daugavpils University, Latvia

Anita Pipere

Daugavpils University, Latvia

\begin{abstract}
The causes for the partnership problems and low birth-rate can be looked upon not only through an economical discourse, but also via the thorough exploration of psychological determinants of sustainable family relationships. The skills and abilities for the development of such relationships significantly depend on the characteristics of childhood family experience. Exploring the factors that influence partnership quality and birth-rate in Latvia 221 respondents were surveyed (185 women and 36 men) aged from 20 to 40 . Majority of the sample indicated to their negative childhood experience (mostly parents' conflicts, divorce, neglect, alcohol abuse) and admitted an impact of this experience on their partnership in adulthood. The respondents with negative childhood family experience reported conflicts in their current relationships more often than their counterparts with supportive childhood experience. The most frequent partnership problems appeared to be emotional violence and computer addiction, at much less rate - alcohol abuse. Though, the statistically significant correlations between the childhood family experience and the partnership problems as well as between the childhood family experience and number of children in family were not found in the given sample. The problem of drug addiction had a statistically significant negative correlation with the number of children in family. Future research could focus on the ways in which positive and adverse childhood experiences interact to influence partnership quality and birth-rate.
\end{abstract}

Keywords: adulthood, birth-rate, childhood family experience, family, partnership problems.

\section{Introduction}

The demographical-economic paradox suggests - although the level of economical well-being in the developed countries is very high, the birth rate is still low (i.e., Livingston, 2011; Yashiro, 1998). Therefore, the causes of low birth-rate could be searched for not only in the economical conditions but also, possibly, in such psychological determinants of family formation and wish to have children as skills and abilities of partners to create and sustain healthy, emotionally stable relationships based on mutual respect, trust and equality. Among other factors, such skills and abilities can be determined by the characteristics of childhood family experience. Since each society has its own 
unique economical, social, cultural and environmental conditions, study was conducted in Latvia (2012-2013) aiming to explore the possible psychological causes of low birth-rate and focusing both on individual issues and relationship problems. Considering the volume of present paper, only those data from this study will be analysed that relate to following research questions:

1) How common is positive or negative childhood family experience among the studied sample?

2) What are the views of respondents about the impact of their own childhood family experience on the quality of their partnership in adulthood?

3) What is the difference between the groups of respondents with negative and positive childhood family experience in terms of the quality of their partnership in adulthood?

4) How common are disfunctional partnership and what are the relationships between the childhood family experience and disfunctional partnership in adulthood and between the childhood family experience and number of children in adulthood?

5) What kind of relationships exist between the disfunctional partnership and number of children in family?

\section{Theoretical background}

The recent studies have shown that the childhood experience can have a permanent influence on an individual's life (e.g., Rutter, Kim-Cohen \& Maughan, 2006; Whitfield et al., 2003). Supportive childhood family experiences are related to positive adult outcomes, while negative or traumatic childhood family experiences are associated with an array of lasting psychosocial problems in later life (Anda et al., 2006; Felitti et al., 1998). The Adverse Childhood Experience (ACE) Study suggests ten categories of negative childhood family experience: emotional/physical/sexual violence, emotional/physical neglect, substance abuse, mental conditions within the family, violence against a mother or step mother, divorced or parents living separately and the prison record of a family member (Felitti, 2003).

Considering the impact of both positive and negative childhood family experience on partnership quality in adulthood, secure attachment in childhood is associated with satisfying and secure personal relationships in adulthood (Feeney, 2008). Positive familial experiences are also connected with pronounced social competence, civic engagement, and trust and tolerance in social groups and institutions (Fukuyama, 1999; Putnam, 1995). Supportive parent-child relationships were related to such positive qualities as planfulness, independence, social skills, and trusting and tolerant attitudes (Price-Robertson 
et al., 2010). According to the data from ACE Project, adverse childhood experience among other problems underlies reproductive health, sexual behavior, alcohol and drug abuse, instability of relationships that are strongly connected with the quality or partnership and birth-rate (Anda et al., 2006). The study also show the indirect effect of adverse childhood experience on partner aggression via posttraumatic stress disorder (Swopes et al., 2014). Among women, there was a strong graded relationship between the number of adverse childhood experiences and the risk of being a victim of intimate partner violence (Whitfield et al., 2003). Noteworthy also were the connections between adverse childhood family experiences and lower wellbeing in early adulthood (PriceRobertson et al., 2010).

Constructing a study involving the problem outcomes of adverse childhood experience, several types of problems, mostly overlapping those encountered in childhood, need to be considered. For instance, in the large-scale Australian study, measures of long-term health problems, depression, anxiety, antisocial behaviour and substance use were used as indicators of problem outcomes of adverse childhood experience in early adulthood (Price-Robertson et al., 2010). However, the dysfunctional partnership can suffer also from emotional and physical violence, different types of addiction etc. (Kaslow, 1996).

Although, the search of available literature showed that exploration of connections between the quality of partnership and number of children in family has not been among the burgeoning topics, the study in Latvia's context has found that respondents would like to have more children if they would have good financial situation, adequate possibilities for child-care and good interpersonal relationships in family (Berga et al., 2005).

Following several other studies, the respondents of current study reported their childhood family experiences in a retrospective way. Although, the accuracy of such reports can be impeded by memory loss and recall bias, some studies show that retrospective reports can match other sources of data (i.e., Smart et al., 2005) thus providing useful and reliable information.

\section{Methodology}

Method and procedure. The data have been collected by the survey „The birth-rate in Latvia: Influencing factors" (Pipere \& Tretjakova, 2013) consisting of socio-demographical part to detect the age, gender, family situation, place of living, education, financial situation, number of children, and main part of survey to find out the features related to partnership, childhood family experience, pregnancy and health, parent-child relationships, values and wish to have children, etc. The survey included 28 questions that permitted to obtain both quantitative and qualitative data. The questions were designed, based on 
the studies mentioned above, and were improved in a pilot-study. For this purpose, 100 respondents were questioned about the main reasons of their partnership problems, causes of family sustainability as well as their choice to have children. In the given study only those questions that are associated with partnership problems, childhood family experience and number of children in family will be analysed. The survey was disseminated electronically (by email/uploading in social networks). The aim of the study and principles of research ethics ensuring the anonymity and confidentiality were provided at the introduction of survey.

Sample. The sample consisted of 185 women (average age -30.6 years) and 36 men (average age -32 years). The range of age in the sample was from 20 to 40 years. From the whole sample, $59 \%$ of respondents were parents (42\% - 1 child, $40 \%$ - 2 children, $18 \%$ - 3 children), the rest of the sample $(41 \%)$ did not have children. Each respondent represented one family. Majority of sample were satisfied (29\%) or partly satisfied (44\%) with their current economic situation. From the whole sample, $78 \%$ of respondents had higher education, $7 \%$ of respondents at the time of survey were still studying, while $15 \%$ had secondary education.

\section{Results}

Childhood family experience. Based on the several studies about the negative childhood experience and the results of pilot-study, the survey included questions containing following factors of negative childhood experience: conflicts of parents, divorce, child neglect, alcohol abuse in family, emotional and physical violence. Fig. 1 reflects the distribution of main childhood family experience factors in the studied sample.

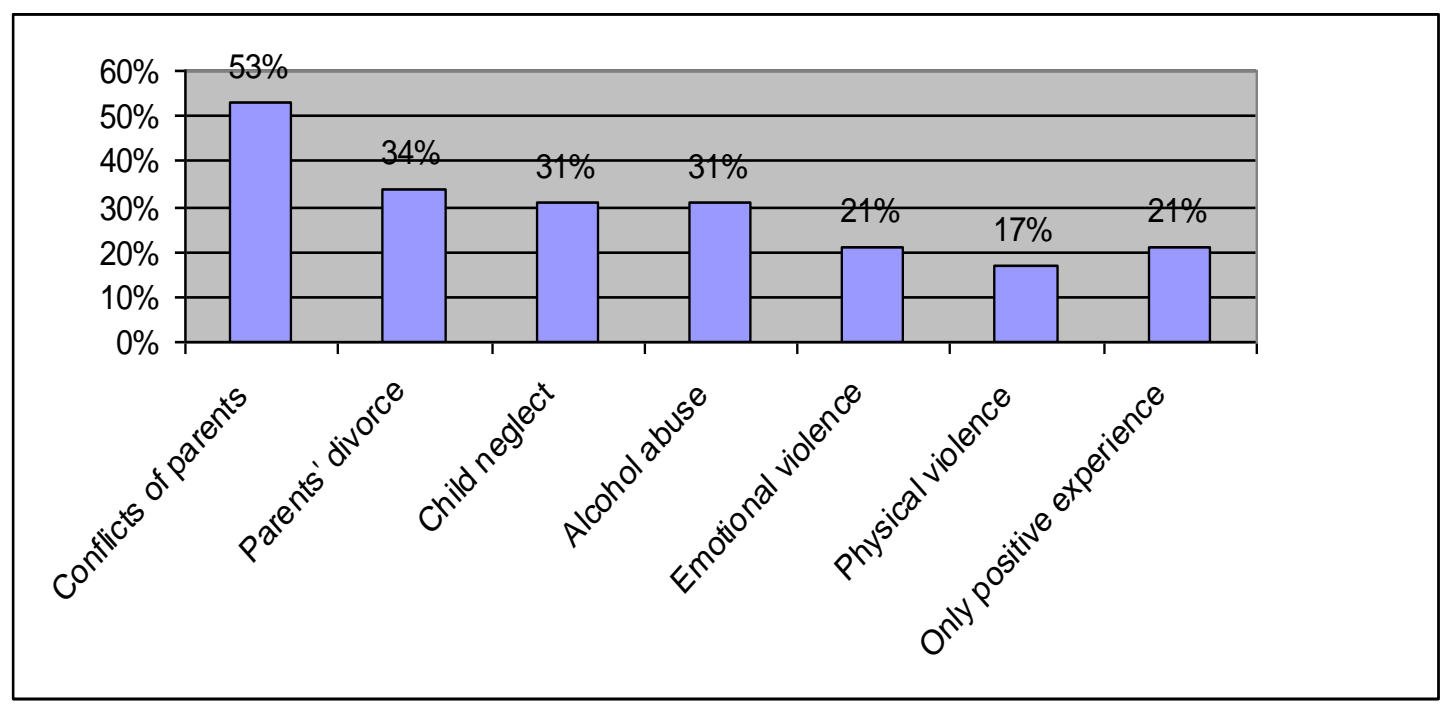

Fig. 1 Percentage of childhood family experience factors $(N=\mathbf{2 2 1})$ 
According to Fig. 1, negative childhood family experience have been recognized by the majority of respondents $(79 \%)$, mere $21 \%$ of respondents have reported only the positive childhood experience. The most frequent negative childhood family experience in this sample were conflicts of parents (53\%), experience of partners' divorce (34\%), child neglect (31\%) and alcohol abuse $(31 \%)$. As the numbers show, large proportion of respondents has experienced several factors of negative childhood family experience.

Views about the impact of childhood family experience on the partnership. Question about the impact of respondents' childhood family experience on the quality of their partnership in adulthood received $67.1 \%$ of positive answers and $17.6 \%$ of negative answers, while $15.3 \%$ of respondents could not provide certain answer to this question. Thus, the personal opinion of the majority of respondents leans toward the recognition of links between their childhood family experience and the quality of their partnership later in adulthood.

Impact of negative and positive childhood family experience in terms of partnership quality. The statistical analysis of impact of negative and positive childhood family experience in terms of partnership quality indicated that conflicts in partnership are observed more frequently for respondents with negative childhood family experience than for those with exclusively positive childhood family experience $(F=3.80 ; p=.049)$ (see Table 1$)$.

Table 1 Difference in partnership aspects for groups with positive and negative childhood family experience $(N=221)$

\begin{tabular}{lccc}
\hline \multicolumn{1}{c}{ Partnership Aspects } & $\begin{array}{c}\text { Evaluation of Childhood } \\
\text { Experience }\end{array}$ & \\
\cline { 2 - 3 } & \multicolumn{2}{c}{$\begin{array}{c}\text { Negative } \\
\text { Positive }\end{array}$} & \\
\hline Feels safe & 3.18 & 3.17 & .987 \\
\hline Mutual trust & 3.34 & 3.37 & .846 \\
\hline Mutual respect & 3.34 & 3.30 & .761 \\
\hline Sharing experience, beliefs, feelings & 3.21 & 3.17 & .793 \\
\hline Constructive discussion of cohabitation issues & 2.93 & 3.00 & .652 \\
\hline Conflicts in relationships & $\mathbf{1 . 4 5}$ & $\mathbf{1 . 2 1}$ & $\mathbf{. 0 4 9}$ \\
\hline Emotional comfort & 2.80 & 2.89 & .572 \\
\hline Emotional separation and loneliness & 1.07 & .95 & .453 \\
\hline Satisfaction with partnership & 2.99 & 2.98 & .988 \\
\hline
\end{tabular}

However, it is interesting to observe, that those with negative childhood experience have evaluated several partnership aspects (feels safe, mutual respect, shared experience and satisfaction with partnership) even slightly higher 
than respondents with positive childhood experience. Although these differences are very small and statistically insignificant, they ask for further investigation.

Partnership problems, the relationships between the childhood family experience, partnership problems and number of children. To obtain information about the partnership problems, the respondents were asked to evaluate their current partnership with regard to the following problems: emotional/physical violence, alcohol abuse, drug addiction, and computer addiction (see Table 2). According to Table 2, the most frequent partnership problems appeared to be emotional violence and computer addiction, at much less rate - alcohol abuse. Physical violence and drug addition were almost nonexistent in given sample. Yet, the statistically significant relationships were not found neither between the childhood family experience and partnership problems in adulthood nor between the childhood family experience and number of children in family.

Table 2 Distribution of answers regarding the partnership problems $(N=\mathbf{2 2 1})$

\begin{tabular}{lccccc}
\hline \multicolumn{1}{c}{ Partnership Problems } & \multicolumn{5}{c}{ Distribution of Answers } \\
\cline { 2 - 6 } & $\begin{array}{c}\text { All the } \\
\text { time (\%) }\end{array}$ & $\begin{array}{c}\text { Frequently } \\
(\mathbf{\%})\end{array}$ & $\begin{array}{c}\text { Sometimes } \\
(\mathbf{\%})\end{array}$ & $\begin{array}{c}\text { Seldom } \\
(\boldsymbol{\%})\end{array}$ & $\begin{array}{c}\text { Never } \\
(\boldsymbol{\%})\end{array}$ \\
\hline Emotional violence & 1.40 & 5.40 & 16.7 & 22.5 & 54.1 \\
\hline Physical violence & .00 & .50 & 1.40 & 5.00 & 93.2 \\
\hline Alcohol abuse & 1.40 & 4.10 & 5.90 & 15.8 & 72.9 \\
\hline Drug addiction & .00 & .90 & .50 & 2.70 & 95.9 \\
\hline Computer addiction & 1.80 & 5.00 & 14.1 & 23.6 & 55.5 \\
\hline
\end{tabular}

Relationship between the partnership problems and number of children in family. Focusing on the relationship between the partnership problems and number of children in family, the data show that only the problem of drug addiction has a statistically significant correlation with the number of children in family $(r=-.16 ; p=.025)$.

\section{Discussion and conclusions}

In the sample consisting mostly of highly educated and financially secure women, similarly as in the study in Australia (Price-Robertson et al., 2010) the respondents have not reported pronouncedly negative childhood experience. However, it is indicative that very large proportion of respondents mentioned at least one category of negative childhood experience. Adverse childhood experiences are surprisingly common, although typically concealed and 
unrecognized (Felitti, 2003). The large study in Latvian context shows that only $16.9 \%$ of respondents in total had not had any adverse experiences before they had turned 18. More women than men scored higher on an ACE score, as did ethnic Russians and respondents with other ethnicity and also respondents with a low socioeconomic status (Velika et al., 2012). Majority of respondents in presented study has admitted that their childhood family experience has an influence on the quality of their partnership, that illustrate the self-awareness skills of the sample and also provides certain justification for the empirical study on the relationships between these variables. The analysis of the impact of negative and positive childhood family experience in terms of partnership quality shows that the most frequent childhood family problem - parents conflicts have been transferred also to the later life of adults - those who have negative childhood family experience encounter conflicts in their partnership more often than their counterparts with supportive childhood experience. Several other studies also have shown the possibility of intergenerational transmission of violence in interpersonal setting (Black et al., 2010; Egeland, 1993). In terms of dysfunctional partnership, it seems that high socially economical status and gender determined the most frequent problem - emotional violence. Only about a half of sample has never experienced emotional violence in their partnership, suggesting to the perpetuating cycle of violence also for the children growing up in the families of respondents. Similary as in Australian study (Price-Robertson et al., 2010), relationships between the childhood experience and dysfunctional partnership were not common. Also, the relationships were not found between the childhood experience and number of children in family that could be possibly explained with high educational and economical status of studied sample. One could also assume that the lack of these relationships could be caused by the scarcity of distinctively negative childhood experience, i. e. the predomination of very common and variously perceived and interpreted negative childhood experience like the conflicts of parents. Since drug addiction can be viewed as the most dangerous partnership problem measured in this survey, it seems natural that significant links were found between this problem and number of children in family.

Several limitations were noticed for this study. One of them is the underrepresentation of respondents with low socio-economic status that likely to have led to lower estimates of the adverse childhood experiences and partnership problems as well as lack of relationships between the childhood family experience and family situation (partnership and birth-rate) in adulthood. More narrowly focused studies would be able to include more in-depth measures of targeted variables. Also,childhood family experiences were retrospectively reported, although, it seems that such reports also can provide reliable information (Smart et al., 2005). The implications of this small study would 
Indra Tretjakova, Anita Pipere. The Impact of Childhood Family Experience on Partnership Problems and Birth-Rate in Adulthood

suggest to routinely seek a history of adverse childhood experiences from the clients of psychological consultation and family therapy dealing with partnership problems. Future research could build on the current findings by identifying the ways in which positive and adverse childhood experiences interact to influence partnership quality and birth-rate. Also, the gender differences in terms of the studied questions would be an appropriate target for the further exploration.

\section{References}

Anda, R. F., Felitti, V. J., Bremner, J. D., Walker, J. D., Whitfield, C., Perry, B. D. et al. (2006). The enduring effects of abuse and related adverse experiences in childhood. A convergence of evidence from neurobiology and epidemiology. European Archives of Psychiatry and Clinical Neurosciences, 256 (3), 174-186.

Berga, G., Tiltina, I., Buša, I., \& Dūšelis, S. (2005). Laulību šķiršanas, laulību noturības un dzimstības veicinošo faktoru izpēte [The study of the factors promoting divorce, marriage resilience and birthrate]. LR Bērnu un gimenes lietu ministrija.

Black, D. S., Sussman, S., \& Unger, J. B. (2010). A further look at the intergenerational transmission of violence: Witnessing interparental violence in emerging adulthood. Journal of Interpersonal Violence, 25 (6), 1022-1042.

Egeland, B. (1993). A history of abuse is a major risk factor for abusing the next generation. In R. J. Gelles \& D. R. Loseke (Eds.), Current controversies on family violence (pp. 197-208). Newbury Park, CA: Sage Publications.

Feeney, J. A. (2008). Adult romantic attachment: Developments in the study of couple relationships. In J. Cassidy \& P. R. Shaver (Eds.), Handbook of attachment: Theory, research, and clinical applications (2nd ed.). New York: The Guilford Press.

Felitti, V. J. (2003). The origins of addiction: Evidence from the adverse childhood experiences study. English version published in Germany as: Felitti, V. J. Ursprünge des Suchtverhaltens - Evidenzen aus einer Studie zu belastenden Kindheitserfahrungen. Praxis der Kinderpsychologie und Kinderpsychiatrie, 2003; 52: 547-559.

Felitti, V. J., Anda, R. F., Nordenberg, D., Williamson, D. F., Spitz, A. M., Edwards, V. et al. (1998). Relationship of childhood abuse and household dysfunction to many of the leading causes of death in adults. The ACE study. American Journal of Preventive Medicine, 14 (4), 245-258.

Fukuyama, F. (1999). The great disruption: Human nature and the reconstitution of social order. New York: Free Press.

Kaslow, F. W. (1996). Handbook of relational diagnosis and dysfunctional family patterns. Wiley-Interscience.

Livingston, G. (2011). In a down economy, fewer births. Pew Research Center.

Pipere, A., \& Tretjakova, I. (2013). Sociālās un uzvedības veselības problēmas gimenē un to saistība ar dzimstības rādìtājiem [Social/behavioral health problems in family and their links to birth-rate]. International Conference „Psychology in Health Care”, Riga, October 7, 2013.

Price-Robertson, R., Smart, D., \& Bromfield, L. (2010). Family is for life: Connections between childhood family experiences and wellbeing in early adulthood. Family Matters, 2010, Nr. 85. 
Putnam, R. (1995). Bowling alone: America's declining social capital. Journal of Democracy, $6(1), 65-78$.

Rutter, M., Kim-Cohen, J., \& Maughan, B. (2006). Continuities and discontinuities in psychopathology between childhood and adult life. Journal of Child Psychology and Psychiatry and Allied Disciplines, 47 (3-4), 276-295.

Smart, D., Richardson, N., Sanson, A., Dussuyer, I., Marshall, B., Toumbourou, J. W. et al. (2005). Patterns and precursors of adolescent antisocial behaviour: Outcomes and connections. Third report. Melbourne: Institute of Family Studies and Crime Prevention.

Swopes, R.M., Simonet, D.V., Jaffe, A.E., Tett, R.P., \& Davis, J.L. (2014). Adverse childhood experiences, posttraumatic stress disorder symptoms, and emotional intelligence in partner aggression. Violence and Victims, 28 (3), 513-530.

Velika, B., Pudule, I., Grinberga, D., Springe, L., \& Gobina, I. (2012). Adverse childhood experiences of young adults in Latvia. Centre for Disease Prevention and Control.

Yashiro, N. (1998). The economic factors for the declining birthrate. Review of Population and Social Policy, 7, 129-144.

Whitfield, C. L., Anda, R. F., Dube, S. R., \& Felitti, V. J. (2003). Violent childhood experiences and the risk of intimate partner violence in adults: Assessment in a large health maintenance organization. Journal of Interpersonal Violence, 18 (2), 166-185. 